\title{
Importance of Sleep for Health and Wellbeing Amidst COVID-19 Pandemic
}

\author{
Kamalesh K. Gulia ${ }^{1}$ (D) - Velayudhan Mohan Kumar ${ }^{2}$
}

Accepted: 21 April 2020 / Published online: 4 May 2020

(c) Springer Nature Singapore Pte Ltd. 2020

While welcoming the new decade 2020 of twenty-first century, the world witnessed the outbreak of the new Coronavirus disease. This novel Coronavirus (SARS-CoV-2) that possibly originated from Wuhan city in Hubei province of China in mid-December 2019 led to Coronavirus disease 2019 (COVID-19) as termed by the World Health Organization. COVID-19 soon became pandemic affecting people across the world. Though COVID-19 can affect any person, the recent data from the United States indicated that COVID-19 fatality was highest in aged persons, while it was considerably less among young and middle aged. Good sleep is important for good health and wellbeing of all age groups, but it is more important for this vulnerable section of our society. Even otherwise, older people tend to have a harder time falling asleep, and more trouble staying asleep. Older people spend more time in the lighter stages of sleep. Moreover, prevalence of sleep disorders is higher among older adults [1]. The escalating levels of stress due to emergent lockouts in affected areas/cities/town would also be aggravating their sleep problems. Immune responses are compromised by various kinds of stress [2, 3]. In the present scenario, it is a serious concern as the Coronavirus attacks the immune system [4]. There are robust evidences to suggest the role of sleep in strengthening immunity $[3,5]$. A recent study in China showed that social support can help in improving sleep quality of healthcare providers involved in COVID-19 management by reducing their anxiety and prevalent stress [6]. This also reflects on the Darwinian theory of biological evolution which emphasized on better survival of

Kamalesh K. Gulia

kkguliak@hotmail.com

1 Division of Sleep Research, Department of Applied Biology, Biomedical Technology Wing, Sree Chitra Tirunal Institute for Medical Sciences and Technology, Trivandrum, Kerala 695012, India

2 Kerala Chapter Convenor, National Academy of Medical Sciences (India), Ansari Nagar, New Delhi 110029, India the individuals who attain ability to compete and survive by attaining better immunity naturally in difficult unpredictable circumstances in the world. So, under the present difficult circumstances, sleep which occupies nearly one-third of our life should get more emphasis for attaining better immunity.

The epidemics of previous Coronavirus variants, severe acute respiratory syndrome in 2002 and Middle East respiratory syndrome in 2012 are still fresh in mind. The fast spread of COVID-19, and limited options of treatment, place a humongous stress on society at various levels. The old dictum that prevention is better than cure needs to be practiced on a larger scale to prevent outbreak of COVID-19 based on the data of its spread in China, Italy, UK, Japan etc. With demands increasing beyond the available facility, the healthcare personnel are overburdened. Moreover, these health workers risk their own lives while treating the diseased. The message needs to be spread that recuperative sleep will enhance their immunity against novel Coronavirus, even amongst these healthcare personnel. Not only these health workers, but also every person having primary or secondary contact with the diseased should have sufficient rest and sleep. The slogan by World Sleep Society for the World Sleep Day 2020 was 'Better Sleep, Better Life, Better Planet'. This is meant to highlight the importance of sleep as a pillar of health, allowing for better decision making and cognitive understanding even in big issues like the Coronaviruses that are affecting the entire planet. There is no harm in emphasising or relying on traditional wisdom like yoga and meditation in achieving better sleep. Ayurveda, the traditional school of Indian medicine, considers sleep (nidra) as one of the three pillars of good health [7-9].

\section{References}

1. Gulia KK, Kumar VM. Sleep disorders in the elderly: a growing challenge. Psychogeriatrics. 2018;18:155-65. 
2. McEwen BS. Central effects of stress hormones in health and disease: Understanding the protective and damaging effects of stress and stress mediators. Eur J Pharmacol. 2008;583(2-3):174-85. https://doi.org/10.1016/j.ejphar.2007.11.071 (Epub 2008 Jan 30. Review).

3. Zielinski MR, Krueger JM. Sleep and immunity. Front Biosci (Schol Ed). 2011;3:632-42 (Review).

4. Li G, Fan Y, Lai Y, Han T, Li Z, Zhou P, Pan P, Wang W, Hu $\mathrm{D}$, Liu $\mathrm{X}$, Zhang Q, Wu J. Coronavirus infections and immune responses. J Med Virol. 2020;92(4):424-32. https://doi. org/10.1002/jmv.25685 (Epub 2020 Feb 7. Review).

5. Dimitrov S, Lange T, Goutefangeas C, Jensen ATR, Szczepanski M, Lehnnolz J, Soekadar S, Rammensee HG, Born J, Besedovsky L. Gos-coupled receptor signaling and sleep regulate integrin activation of human antigen-specific T cells. J Exp Med. 2019;216:517-26.

6. Xiao H, Zhang Y, Kong D, Li S, Yang N. The effects of social support on sleep quality of medical staff treating patients with Coronavirus Disease 2019 (COVID-19) in January and February in China. Med Sci Monit. 2020;5(26):e923549.
7. Carden KA. Sleep is essential: a new strategic plan for the American Academy of sleep medicine. J Clin Sleep Med. 2020;16:1-2. https://doi.org/10.5664/jcsm.8156 (Epub 2019 Dec 10).

8. Gulia KK, Kumar VM. Sleep medicine in ayurveda. Sleep Med Rev. 2016;25:131.

9. Gulia KK, Radhakrishnan A, Kumar VM. Approach to sleep disorders in the traditional school of indian medicine: alternative medicine II. In: Chokroverty S, editor. Sleep disorders medicine: basic science, technical considerations and clinical aspects, chapter 57. 4th ed. New York: Springer; 2017. p. 1221-1232 (ISBN 978-1-4939-6578-6).

Publisher's Note Springer Nature remains neutral with regard to jurisdictional claims in published maps and institutional affiliations. 